\title{
DO CONTIGENCIAMENTO AO ESTADO DE COISAS INCONSTITUCIONAIS: A INTERVENÇÃO DO JUDICIÁRIO NA EXECUÇÃO DA POLÍTICA PENITENCIÁRIA
}

Isabelly Cysne Augusto Maia ${ }^{1}$

Pedro Henrique Azevedo Lopes Ferreira ${ }^{2}$

Resumo:Tem-se que a política pública penitenciária encontra dificuldades de ser implementada nos termos em que foi estabelecida pela legislação específica, ensejando violação a dimensão objetiva dos direitos fundamentais dos encarcerados. Tal situação viabiliza a declaração de um Estado de Coisas Inconstitucionais, o qual produz como consequência a intervenção judicial, inclusive sobre o orçamento da política pública deficitária. O objetivo do presente trabalho está em compatibilizar a dimensão autorizativa do orçamento com os limites da intervenção judicial na sua execução, elucidando que essa intervenção apenas deve ocorrer em situações em que o mínimo existencial dos direitos fundamentais não está sendo concretizado

Palavras-chave: Contigenciamento; Política Penitenciária; Estado de Coisas Inconstitucionais; Orçamento; Ativismo judicial

\section{CONTAINMENT TO THE STATE OF UNCONSTITUTIONAL THINGS: THE INTERVENTION OF THE JUDICIARY IN THE EXECUTION OF THE PENITENTIARY POLICY}

\begin{abstract}
The penitentiary public policy finds it difficult to be implemented in terms of which it has been established by the specific legislation, which violates the objective dimension of the fundamental rights of the imprisoned. Such a situation makes it possible to declare a state of unconstitutional things, which results in judicial intervention, including the budget for deficit public policy. The objective of this work is to reconcile the authorising dimension of the budget with the limits of the judicial intervention, elucidating that this intervention should only occur in situations where the minimum existential rights Fundamentals is not being fulfilled
\end{abstract}

Keywords: Containment; Penitentiary policy; State of unconstitutional things; Budget; Judicial activism

\footnotetext{
${ }^{1}$ Mestranda do Programa de Pós-Graduação em Direito pela Universidade Federal do Ceará. Pós-Graduanda em Direito Administrativo pela PUC-Minas. Bacharela em Direito pela Universidade Federal do Ceará (Magna cum laude). Integrante do grupo de pesquisa "Serviços Públicos e Condições de Efetividade". Editora de seção da Revista NOMOS, Periódico vinculado ao Programa de Pós Graduação da Universidade Federal do Ceará.

${ }^{2}$ Possui graduação em Direito pelo Centro Universitário Christus (2013). Especialização em Direito Constitucional pela Faculdade Entre Rios do Piauí (2014). Mestrando em Direito pela Universidade Federal do Ceará (UFC). Servidor do Ministério Público do Estado do Ceará. Tem experiência na área de Direito, com ênfase em Direito Constitucional, Direito Administrativo, Direito Civil e Direito Processual Civil.
} 


\section{INTRODUÇÃO}

Considerando que o principal mecanismo de financiamento da política pública penitenciária é o Fundo Penitenciário Nacional (FUNPEN), instituído em 1994, pela Lei Complementar $n^{\circ} 79$ e regulamentado pelo Decreto $n^{\circ} 1.093$, de 23 de março de 1994, o qual apresenta como receitas os recursos advindos das custas judiciais recolhidas em favor da União, arrecadação dos concursos de prognósticos, sorteios e loterias (no âmbito federal), bem como recursos confiscados ou provenientes da alienação dos bens perdidos em favor da União, multas decorrentes de sentenças penais condenatórias com trânsito em julgado, fianças quebradas ou perdidas, e rendimentos decorrentes da aplicação de seu patrimônio, questiona-se: Por que a situação penitenciária do Brasil encontra-se em situação crítica? Faz-se necessária a destinação de maior parcela do orçamento ao financiamento dessa política?

Em mais de uma pesquisa efetuada pela Organização Não Governamental Contas Abertas, constatou-se que em 2016 havia por volta de R\$ 3,3 bilhões disponíveis no FUNPEN. Mesmo assim, a dotação orçamentária para 2016 fora de 682,7 milhões, e em outubro tãosomente 270,6 milhões haviam sido devidamente executados. Anotou-se ainda que R \$12,2 milhões tinham sido destacados como reserva de contingência, cujos recursos na prática são dificilmente utilizados e apenas corroboram para o alcance dos resultados fiscais. Em 2017, a referida ONG estima que há um montante de R\$ 2,5 bilhões “parados” no Fundo, destinados para o alcance do superávit primário.

Pelo exposto, percebe-se que a inefetividade na prestação da política pública penitenciária não está na falta de recursos, mas sim na gestão do gasto público, uma vez que os elevado níveis de reserva de contingência, sem a apresentação de qualquer motivação pelo Administrador de porque essas verbas devem ser contingenciadas e não executadas, faz com que a característica de orçamento autorizativo seja compreendida, erroneamente, como direito a não executar a lei orçamentária aprovada.

Para além dos expressivos percentuais de contingenciamento, destaca-se que com a aprovação da Medida Provisória n 781/2017 houve desvio no emprego de verbas do FUNPEN para outras áreas que não estão albergadas pelas finalidades do fundo, como, por exemplo, a possibilidade de utilizar suas receitas para financiar estudos de inteligência policial. Outra dificuldade a ser enfrentada está no corte significativo que a MP empreendeu em suas verbas, mediante a diminuição no valor das custas judiciais da União, uma das principais fontes de custeio do FUNPEN. 
Cita-se, ainda, a falta de transparência que envolve a política pública penitenciária, haja vista a desatualização dos dados governamentais sobre a situação dos presídios no Brasil - o último DEPEN em números data de 2014 -, bem como a defasagem nos números do FUNPEN, tanto no que diz respeito a receitas quanto a gastos - o último FUNPEN em números é de 2012 -, ou seja, os dados disponíveis são os fornecidos por ONGS que trabalham na fiscalização do gasto público, mas não se tratam de informações oficiais, o que demonstra a disposição estatal em dificultar o controle social sobre a política analisada.

Diante dos problemas apresentados e considerando que a efetivação de todo e qualquer direito constitucionalmente previsto demanda a realização de gastos orçamentários, tem-se que a inefetividade do gasto público no que concerne o sistema penitenciário conduziu a uma situação de violação massiva e estrutural dos direitos fundamentais dos encarcerados, o que acarretou a declaração de um Estado de Coisas Inconstitucionais (ECI) sobre essa realidade.

O Estado de Coisas Inconstitucionais é um instituto de origem Colombiana e foi aplicado pela primeira vez em 1997. Por apresentar como principal objetivo a superação das omissões inconstitucionais não normativas, o Estado de Coisas Inconstitucionais conduz ao controle de constitucionalidade de políticas públicas, em que o Judiciário constata a omissão estatal e a violação massiva aos direitos fundamentais de certos grupos sociais e tende a elaborar ou reformular a política pública de forma unilateral, intervindo diretamente no orçamento destinado a execução da política que se apresenta de forma ineficiente.

No Brasil, o Estado de Coisas Inconstitucionais foi declarado em setembro de 2015, por meio da decisão cautelar da $\operatorname{ADPF} \mathrm{n}^{\circ} 347$, oportunidade em que ficou consignada a obrigatoriedade de realização das audiências de custódia em todo o território nacional no prazo de noventa dias e o imediato descontingenciamento das verbas do Fundo Penitenciário Nacional (FUNPEN), um dos principais entraves ao custeio da política penitenciária.

Ocorre que a referida decisão não produziu os efeitos esperados, sobretudo pela falta de fixação de um mecanismo de fiscalização pelo Supremo. Para além do reiterado descumprimento ao mandamento judicial, haja vista que as verbas do FUNPEN continuaram a ser contingenciadas, destaca-se a aprovação da MP n 781/2017 que autoriza a dispersão de receitas do fundo para outras áreas sem qualquer vinculação com a política penitenciária, reduzindo ainda mais os recursos disponíveis para o financiamento dessa política.

Assim, acredita-se que as reservas de contingencia em patamares elevados conduziram ao Estado de Coisas Inconstitucionais e diante da situação periclitante em que o sistema penitenciário se encontra torna-se premente a intervenção judicial sobre a execução 
orçamentária, com o fito de minimizar as distorções no gasto público, sobretudo se considerarmos que o orçamento é lei também em sentido material e, por isso, não há direito a não execução orçamentária.

A fim de compatibilizar a dimensão autorizativa do orçamento com a intervenção judicial na execução do orçamento, empreendeu-se análise documental dos dados oficiais acerca do contingenciamento nas receitas do FUNPEN, bem como se investigou a inefetividade das ordens judiciais traçadas após a declaração do Estado de Coisas Inconstitucionais, sobretudo pela falta de mecanismos de fiscalização no cumprimento da decisão, revelando que a intervenção judicial na execução orçamentária deve ocorrer mediante a promoção do diálogo entre os poderes políticos, cabendo ao judiciário apenas fiscalizar a execução do plano de ação elaborado por esses. Defende-se, ainda, que essa intervenção apenas poderá ocorrer em casos extremos, em que o mínimo existencial dos direitos fundamentais não está sendo concretizado. Assim, não é qualquer limitação na prestação de direitos que deve ensejar a intervenção judicial, afinal o orçamento é limitado e as escolhas trágicas cabem ao administrador.

Complementando a pesquisa documental, realizou-se estudo bibliográfico, com o desiderato de analisar a posição doutrinária acerca da possibilidade de intervenção judicial na execução do orçamento, diante da dimensão autorizativa desse. Afinal, encarar o orçamento como mera peça contábil e lei em sentido apenas formal é conferir ao Executivo amplíssimo nível de discricionariedade, comprometendo, inclusive, a efetivação do mínimo existencial dos direitos fundamentais de minorias sociais com baixa ou ausente representação política, tornando necessária a intervenção judicial nesses casos em que a dimensão autorizativa se confunde com direito a não execução.

Nesse sentido, defendeu-se a possibilidade do judiciário intervir na execução orçamentária, sobretudo quando verificada displicência com o gasto público. Acredita-se que tal intervenção deve ocorrer por meio da consolidação de um Compromisso Significativo, e que a decisão judicial será resultado do diálogo entre os poderes políticos para que haja a superação de bloqueios institucionais e políticos. Assim, ao Judiciário caberia apenas fiscalizar o plano de ação formulado pelo Executivo e Legislativo.

Propõe-se que haja a declaração do Estado de Coisas Inconstitucionais quando verificada situação de violação massiva a direitos fundamentais de certo grupo, acarretada, sobretudo, pela não aplicação das rubricas orçamentárias, sem apresentação de qualquer motivação congruente para assim proceder. Após a declaração do ECI, o judiciário convoca aos poderes políticos para que tracem planos de ação, especificando como irão realizar o gasto 
público, a fim de melhorar a prestação da política que se encontra deficitária. Defende-se, assim, que a intervenção do judiciário na execução do orçamento não pode ser no sentido de impor como o gasto público deve ser realizado, mas sim indicar que há problemas na gestão orçamentária e que essa deve ser revista, aplacando a discricionariedade contra legem.

Inclusive, essa é a proposta do Projeto de Lei nº 736 de 2015, o qual determina que, quando ocorrer a constatação do ECI, cabe ao Judiciário motivar o diálogo entre os poderes políticos competentes para a formulação da política pública adequada, monitorando a execução das obrigações assumidas, portanto, não retira da política a atribuição de formular e reestruturar as políticas públicas que se mostram faticamente ineficientes.

Este artigo está organizado do seguinte modo. No primeiro tópico demonstrou-se a ineficiência do gasto público no que concerne a política pública penitenciária, evidenciando que a atuação administrativa está impossibilitando a prestação desse serviço, haja vista os elevados níveis de contingenciamento e a consequente falta de investimento nessa seara.

Em seguida, demonstrou-se como a falta de compromisso com o gasto público impede a concretização de direitos fundamentais, considerando que todos esses demandam a realização de gastos para serem efetivados, produzindo um Estado de Coisas Inconstitucionais, uma vez que o não financiamento do serviço gera impossibilidade de acesso a direitos, tornando necessária a intervenção judicial na tentativa de corrigir os desvios com o gasto público, impelindo o Executivo a cumprir a lei orçamentária nos termos em que foi aprovada.

Por fim, analisou-se como a intervenção judicial na execução orçamentária deve ocorrer, indicando que após a declaração do Estado de Coisas Institucionais, ao judiciário não cabe indicar como e quanto da receita pública deve ser empregada, mas sim coibir a atuação ilícita do Executivo, evidenciando que a dimensão autorizativa do orçamento não significa direito a não execução orçamentária, impelindo tal poder a traçar, em consonância com o legislativo, um plano de ação voltado à efetivação da política judicializada, o que conferirá, inclusive, maior transparência na realização do gasto. O judiciário fiscalizará a execução do plano e fixará mecanismos sancionatórios quando esse não for cumprido.

\section{DO CONTINGENCIAMENTO DO FUNDO PENITENCIÁRIO NACIONAL A INEXECUÇÃO DA POLÍTICA PÚBLICA PENITENCIÁRIA.}

O Fundo Penitenciário Nacional (FUNPEN) apresenta natureza jurídica de Fundo Especial, cuja previsão está nos artigos 71 a 74 da Lei 4.320, de 17 de março de 1964, constituindo, em verdade, “instrumentos de gestão financeira em que o Estado cria para a 
realização de determinados objetivos” (PETTER, 2010, p. 214). De forma mais específica, o FUNPEN é um Fundo Especial de natureza financeira, uma vez que apresenta destinatários e beneficiários pré-definidos.

Considerando que para os fundos especiais é proibida a destinação do produto da arrecadação de impostos, tendo em vista a vedação contida no artigo 167, IV, da Constituição Federal $^{3}$, tem-se que o FUNPEN é eminentemente financiado com recursos que possuem origem nas dotações orçamentárias da União, em custas judiciais recolhidas em favor deste mesmo ente federativo, arrecadação dos concursos de prognósticos, sorteios e loterias (no âmbito federal), bem como recursos confiscados ou provenientes da alienação dos bens perdidos em favor da União, multas decorrentes de sentenças penais condenatórias com trânsito em julgado, fianças quebradas ou perdidas, e rendimentos decorrentes da aplicação de seu patrimônio.

Nesse sentido, os Artigos $1^{\circ}$ e $2^{\circ}$ do Decreto $n^{\circ} 1.093 / 94^{4}$ especificam minuciosamente em que atividades os recursos do FUNPEN podem ser aplicados. Ademais, como bem prescreve o Artigo $73^{5}$ da Lei $n^{\circ} 4.320 / 64$, os recursos de um fundo têm sua utilização vinculada aos objetivos que o instituiu, não podendo ser utilizados para despesas que não se identifiquem diretamente com a realização de seus objetivos ou serviços determinados. Assim, se ao final do exercício financeiro existir saldo positivo no fundo especial, esse saldo não poderá ser aplicado para execução de outro serviço público, mas deve ser revertido em crédito, a favor do próprio fundo especial.

\footnotetext{
${ }^{3}$ Art. 167. São vedados: IV - a vinculação de receita de impostos a órgão, fundo ou despesa.

${ }^{4}$ Art. $1^{\circ}$ O Fundo Penitenciário Nacional (FUNPEN), instituído pela Lei Complementar no 79, de 7 de janeiro de 1994, tem por finalidade proporcionar recursos e meios destinados a financiar e apoiar as atividades e os programas de modernização e aprimoramento do Sistema Penitenciário Brasileiro.

Art. $2^{\circ}$ Os recursos do FUNPEN serão aplicados: I - na construção, reforma, ampliação e reequipamento de instalações e serviços de penitenciárias e outros estabelecimentos prisionais; II - na manutenção dos serviços penitenciários, mediante a celebração de convênios, acordos, ajustes ou contratos com entidades públicas ou privadas; III - na formação, aperfeiçoamento e especialização de servidores das áreas de administração, de segurança e de vigilância dos estabelecimentos penitenciários; IV - na formação educacional e cultural do preso e do internado, mediante cursos curriculares de $1^{\circ}$ e $2^{\circ}$ graus, ou profissionalizantes de nível médio ou superior; $\mathrm{V}$ na elaboração e execução de projetos destinados à reinserção social de presos, internados e egressos; VI - na execução de programas voltados à assistência jurídica aos presos e internados carentes; VII - na execução de programas destinados a dar assistência às vítimas de crime e aos dependentes do preso ou do internado; VIII - na participação de representantes oficiais em eventos científicos, realizados no Brasil e no exterior, sobre matéria penal, penitenciária ou criminológica; IX - nas publicações e na pesquisa científica na área penal, penitenciária ou criminológica; $\mathrm{X}$ - nos custos decorrentes de sua própria gestão, excetuadas as despesas de pessoal referentes a servidores públicos que já percebem remuneração dos cofres públicos. Parágrafo único. Na aplicação dos recursos do FUNPEN, o Departamento de Assuntos Penitenciários observará os critérios e prioridades estabelecidos pela Secretaria dos Direitos da Cidadania e Justiça e as resoluções do Conselho Nacional de Política Criminal e Penitenciária.

${ }^{5}$ Art. 73: Salvo determinação em contrário da lei que o instituiu, o saldo positivo do fundo especial apurado em balanço será transferido para o exercício seguinte, a crédito do mesmo fundo.
} 
Não obstante a existência de um Fundo específico, criado ainda na década de noventa, e exclusivamente voltado para o financiamento da política pública penitenciária, percebe-se que a situação carcerária no Brasil enfrenta uma severa crise, em que os direitos fundamentais mais básicos dos custodiados não são respeitados.

Conforme dados extraídos das Informações Penitenciárias (INFOPEN/2014), elaborado pelo Ministério da Justiça, com a participação direta do DEPEN, observa-se que a população carcerária brasileira é a quarta maior do mundo com 622.202 mil encarcerados, perdendo apenas para Estados Unidos, China e Rússia. Dessa forma, para atender a demanda por vaga o país teria que aumentar em 50\% o número de vagas existentes (MINISTÉRIO DA JUSTIÇA. DEPEN, 2014, p. 14).

Nos últimos 14 anos a população do sistema prisional brasileiro teve um aumento de 167,32\%, muito acima, portanto, do crescimento demográfico (MINISTÉRIO DA JUSTIÇA. DEPEN, 2014, p. 18), aumento que reflete a existência de uma política criminal encarceradora. Dessa maneira, a solução do problema não está no simples aumento do número de vagas, mas, "no envolvimento dos três Poderes da República, em todos os níveis da Federação, além de se relacionar diretamente com o que a sociedade espera do Estado como ator de pacificação social” (MINISTÉRIO DA JUSTIÇA. DEPEN, 2014, p. 06), ou seja, a possível solução para o problema está em uma atuação conjunta, sistêmica e interinstitucional entre todas as esferas de governo.

Conclui-se que a política carcerária encontra-se em crise, sobretudo, em razão da falta de interesse político para promover a execução orçamentária. Nesse sentido, o próprio Ministério da Justiça reconhece o elevado contingenciamento praticado nas verbas do FUNPEN, como se analisa da última publicação do FUNPEN em Números, em que se afirma existir a possibilidade de contingenciar os recursos, pois seriam estes são espécie de transferências voluntárias, ou seja, não decorrem de obrigação constitucional ou legal. “Dessa forma, suas dotações orçamentárias fazem parte da chamada base contingenciável que o Governo Federal dispõe para obtenção de seu superávit primário” (FUNDO PENITENCIÁRIO NACIONAL EM NÚMEROS, 2012, p. 140).

Historicamente, as verbas do FUNPEN são amplamente contingenciadas, impedindo que os objetivos para os quais o fundo foi instituído sejam alcançados. Em 2011, o orçamento autorizado do fundo fora de R\$ 269,9 milhões, ao passo que orçamento utilizado atingiu apenas R\$ 98,3 milhões, numerário muito inferior à metade da dotação inicial (FUNDO PENITENCIÁRIO NACIONAL EM NÚMEROS, 2012, p. 20). 
Em mais de uma pesquisa efetuada pela Organização Não Governamental Contas Abertas, constatou-se que em 2016 havia por volta de R \$ 3,3 bilhões disponíveis no FUNPEN. Mesmo assim, a dotação orçamentária para 2016 fora de 682,7 milhões, e em outubro tãosomente 270,6 milhões haviam sido devidamente executados. Anotou-se ainda que R\$ 412,2 milhões tinham sido destacados como reserva de contingência, cujos recursos na prática são dificilmente utilizados e apenas corroboram para o alcance dos resultados fiscais (CONTAS ABERTAS, 2017). Em 2017, a referida ONG estima que há um montante de R\$ 2,5 bilhões “parados” no Fundo, destinados para o alcance do superávit primário (CONTAS ABERTAS, 2017).

Observa-se, portanto, que a reserva de contingência realizada no caso do FUNPEN tem produzido uma completa inexecução da política pública penitenciária, deturpando a finalidade prevista na Lei de Responsabilidade Fiscal para a realização de contingenciamentos, os quais deveriam ser efetivados para empreender o ajuste no orçamento, em que a limitação de empenho fica autorizada apenas na hipótese específica do montante de receitas, inicialmente, previsto ser frustrado (LOCHAGIN, 2017, p. 09), ou seja, as verbas apenas podem ser contingenciadas se as receitas previstas não forem auferidas, de modo que a realização de contingência em outras hipóteses que não essa, configura desinteresse político, marcado pelo confronto do Executivo com o Legislativo.

Não existe, portanto, direito a não execução orçamentária pelo gestor público. Conforme aduz Guilherme Waldemar d’Oliveira Martins, a inexecução do orçamento, ensejando modificações na Lei Orçamentária nos termos em que foi aprovada, como por exemplo com o excessivo contingenciamento das verbas disponibilizadas, gera um grave problema de perda de confiança do administrado nos representante do Executivo (MARTINS, 2014, p. 203).

Diante dessa possível consequência de perda de confiança, Guilherme Waldemar defende que a não execução do orçamento só poderá ocorrer em razão de três justificativas: “1. A imprevisibilidade do equilíbrio; 2. A revelação das motivações e a ponderação dos efeitos globais e 3. O cumprimento de uma obrigação jurídica” (MARTINS, 2014, p. 207).

Assim, em razão do desequilíbrio institucional acarretado pela inexecução orçamentária, entende-se que o orçamento apenas poderá não ser executado nos termos em que foi aprovado pelo Legislativo diante de situações de extrema imprevisibilidade ou que se tenha identificado uma forma mais eficiente de realizar o gasto público, o que deve ser previamente autorizado pelo Legislativo. 
Considerando, portanto, as adversas consequências da não execução orçamentária, tem-se que o orçamento deve ser compreendido enquanto lei em sentido material, passível de controle pelo Poder Judiciário. Assim, em 2003, o Supremo Tribunal Federal reconheceu, por meio da Ação Direta de Inconstitucionalidade (ADI) n² 2.925-DF, a possibilidade de exercício do controle concentrado de constitucionalidade sobre as leis orçamentárias. Nessa oportunidade, o Ministro Carlos Ayres Britto, asseverou que a lei orçamentária seria para a Administração Pública, logo abaixo da Constituição, a lei mais importante de nosso ordenamento jurídico e por isso dotada de generalidade e abstratividade capaz de ensejar o controle de constitucionalidade.

Tal posicionamento acerca da possibilidade de controle judicial sobre o orçamento foi reforçado em 2016, por meio da ADI n 5.449-MC, em que o Ministro Teori Zavascki consignou que as leis orçamentárias que materializem atos de aplicação primária da Constituição Federal podem ser submetidas a controle de constitucionalidade em processos objetivos. Assim, o orçamento público passa a ser compreendido como lei dotada de materialidade e substancialidade em seu conteúdo.

Não obstante todas as preocupações em avançar na concepção da natureza jurídica do orçamento, para que esse não seja encarado apenas como uma peça contábil e formalista de receitas e despesas; a tendência predominante ainda é encará-lo enquanto lei de natureza autorizativa, o que significa que o fato de determinada verba estar nele prevista não obriga o governante a realizá-la, apenas o autoriza, não gerando direitos subjetivos a terceiros. Este, aliás, sempre foi o entendimento do Supremo Tribunal Federal, muito embora tal órgão jurisdicional tenha avançado com o reconhecimento da possibilidade de judicialização de políticas públicas e o exercício do controle de constitucionalidade da peça orçamentária (OLIVEIRA, 2017, p. 197).

A discussão em torno da natureza da lei orçamentária, se autorizativa ou impositiva é de somenos importância se considerarmos o desvirtuamento histórico que o orçamento vem sofrendo, mediante modificações reiteradas pelo Executivo, convertendo-o em legislação simbólica, em que há profunda interferência do sistema político no jurídico (NEVES, 2007, p. 66).

Assim, encarar o orçamento como lei que pode ser reiteradamente modificada, ao alvedrio dos interesses políticos, enseja a existência de uma prática que compromete significativamente a efetivação das políticas públicas, ensejando um sistema de inefetividade do texto constitucional. Nesse sentido, Ricardo Lobo Torres aduz que: 
Os direitos fundamentais têm uma relação profunda e essencial com as finanças públicas. Dependem, para a sua integridade e defesa, da saúde e do equilíbrio da atividade financeira do Estado, ao mesmo tempo em que lhe fornecem o fundamento da legalidade e da legitimidade. Os direitos fundamentais se relacionam com os diversos aspectos das finanças públicas. Assim é que o tributo, categoria básica da receita do Estado de Direito, é o preço da liberdade, preço que o cidadão paga para ver garantidos os seus direitos e para se distanciar do Leviatã (TORRES, 2008, 499).

Logo, dando enfoque à política pública penitenciária, percebe-se que o cerne do problema está em não levar o orçamento e o direito financeiro a sério (CONTI, 2016, p. 61), afinal pouco vale destinar mais recursos se esses continuarem a ser mal ou não utilizados.

Constata-se, portanto, que há suficiente dotação orçamentária para o financiamento da política pública penitenciária, entretanto as receitas do FUNPEN são contingenciadas, de forma que o orçamento tem sido encarado como uma mera autorização destinada ao Poder Executivo, tendo esse reiteradamente decidido em utilizar as verbas do FUNPEN para alcançar superávit primário e não em atender as finalidades para as quais esse fundo foi idealizado, em clara afronta às normas infraconstitucionais que regulamentam a utilização de receitas de fundos especiais.

Deve-se destacar ainda o desvio de finalidade na aplicação das verbas do FUNPEN, o que tem sido autorizado por meio da Medida Provisória (MP) $n^{\circ} 781 / 2017$, a qual fora antecedida pela MP n 755/2016.

A MP n 781/2017 autorizou a utilização de capital do FUPEN para o financiamento de programas e atividades preventivas, como a inteligência policial, além de ampliar as atribuições da Força Nacional; revogou o inciso VII do artigo $2^{\circ}$ da Lei Complementar n. ${ }^{\circ}$ 79/94, cortando os 50\% do montante das custas judiciais recolhidas em favor da União, receita que perfazia quantia significativa para o fundo; permitiu a transferência de recursos do FUNPEN para organizações da sociedade civil que administrem estabelecimento penal e viabilizou a transferência de recursos para capacitação e qualificação de profissionais de todo o âmbito da Secretaria Nacional de Segurança Pública.

Conclui-se, portanto, que a MP n 781/2017 permitiu o emprego de verbas do FUNPEN para outras áreas que não estão albergadas pelas finalidades do fundo, além de ter empreendido um corte significativo em suas receitas, com diminuição no valor das custas judiciais da União.

Assim, para além dos históricos níveis de contingenciamento, a política pública analisada ainda enfrenta outros problemas como a falta de transparência, o que dificulta o 
exercício do controle por parte da sociedade civil sobre a utilização das receitas públicas voltadas ao financiamento desse serviço. Destaca-se que o último "FUNPEN em números” foi lançado pelo Ministério da Justiça em 2012 e o último “Levantamento Nacional de Informação Penitenciárias (INFOPEN)” data de 2014, ou seja, nem mesmo as estáticas oficiais acerca do percentual de receitas contingenciadas pelo Governo Federal ou como se encontra a situação nacional dos presídios está atualizada e mais recentemente, a aprovação da inconstitucional Medida Provisória n 781/2017 que autoriza o emprego de verbas do Fundo para outros fins, como o financiamento de inteligência policial.

A não execução orçamentária em razão dos elevados e reiterados níveis de contingenciamento, aliado a falta de transparência acerca da situação penitenciária no Brasil, dificultando o exercício do controle social, bem como a continua descrença da população no Poder Executivo, fenômeno oriundo da desconsideração das previsões orçamentárias por esse poder político, têm ensejado a intervenção do Judiciário sobre o orçamento, na tentativa de estabelecer soluções à violação massiva dos direitos fundamentais mais básicos dos encarcerados. A máxima expressão do intervencionismo judicial ocorreu em setembro de 2015 com a declaração pelo Supremo Tribunal Federal de um Estado de Coisas Inconstitucionais (ECI) sobre o sistema penitenciário brasileiro, por meio da Ação de Descumprimento de Preceito Fundamental (ADPF) n 347.

\section{DA INEFICIÊNCIA DO GASTO PÚBLICO AO ESTADO DE COISAS INCONSTITUCIONAIS}

Considerando que todos os direitos detêm custos para a sua efetivação, quer sejam direitos sociais, que sejam direitos individuais, tem-se que a efetivação do texto constitucional perpassa pela realidade orçamentária. Assim, os custos dos direitos não devem ser encarados como meros óbices a efetivação, mas são, em verdade, meios e pressupostos que tornam possíveis a realização dos direitos.

Os custos não devem ser compreendidos, portanto, como algo externo ao direito, mas sim como um elemento intrínseco a sua efetivação, de forma que não é a exaustão de um determinado orçamento que frustra a efetivação de certo direito fundamental, mas sim a opção política existente por trás da elaboração do orçamento, qual seja: o gasto público (GALDINO, 2005, p. 234/235).

Nesse sentido, o orçamento passa a ter como uma das suas principais finalidades a regulação do gasto (CAVALCANTE, 2014, p. 05). A questão principal passa a ser, portanto, o 
controle das escolhas realizadas pelos gestores de onde e como gastar as receitas públicas, uma vez que os recursos são finitos e todos os direitos necessitam de recursos para serem efetivados.

Assim, chega-se ao paradoxo democrático, em que os representantes de grupos minoritários, pelos mais variados motivos, desviam-se da defesa dos interesses dos seus representados e passam a tomar decisões em atenção a interesses pessoais, de terceiros ou exclusivamente político-partidários (COSTA, 2010, p. 189). Esse é um dos paradoxos da democracia representativa: a vontade dos representantes não é hábil a coincidir com a vontade geral, dos representados. Assim, ocorre que a definição de prioridades no gasto público acaba sendo realizada pelos grupos econômicos e politicamente fortes que controlam o legislativo e o executivo, comprometendo a qualidade do gasto público.

Nesse sentido, Buchanan e Musgrave (1999, p. 122) advertem que:

O Estado democrático sofre de um paradoxo fundamental; as pessoas tendem, na medida em que há um aumento na transferência, a buscar seus interesses imediatos e particulares de classe, grupo, região, profissão, ocupação ou atividade. Desse modo, existe uma contradição fundamental no Estado Democrático, visto que haverá sempre uma crescente demanda por distribuição localizada de recursos e uma capacidade limitada de arrecadação fiscal e financiamento do Estado. O paradoxo das demandas crescentes e resistências à tributação sofre nas disputas entre exigências por distribuição orientada e exigências por justiça e equidade (equity or justice). Muitas das crises fiscais do Estado Democrático se referem à ausência de solução por estas demandas.

Ao se encarar o orçamento enquanto lei meramente autorizativa, vê-se que a definição do gasto público passa a ser um critério meramente político, em que o Executivo decide se, como e onde gastar. O critério eminentemente político conduz, por sua vez, a uma série de incongruências, sobretudo se pensarmos nas políticos públicas voltadas aos grupos de pouca ou nenhuma expressividade política, como é o caso dos presidiários.

Por isso, o caráter eminentemente autorizativo da lei orçamentária “abre margem ao mau gestor para a realização de práticas no campo da discricionariedade administrativa que vão de encontro aos reais objetivos orçamentários” (OLIVEIRA; FERREIRA, 2017, p. 209), contribuindo para o aparecimento de situações de violação massiva de direitos fundamentais, uma vez que esses não são efetivados diante da falta de investimento em políticas públicas que visam sua concretização.

Esse cenário é a exata descrição do que ocorre com a política pública penitenciária. A falta de interesse político em tutelar os direitos fundamentais mais básicos dos encarcerados faz com que o gasto direcionado a política penitenciária seja ínfimo e até mesmo desvirtuado, como ocorreu com a Medida Provisória n 755/2017, o que enseja o aparecimento de situações de violação massiva e estrutural dos direitos desses indivíduos, tornando-se premente a 
intervenção do Poder Judiciário para garantir ao menos o acesso ao núcleo do mínimo existencial desses direitos.

Conforme assevera Ricardo Lobo Torres, a “jusfundamentalidade dos direitos fundamentais se reduz ao mínimo existencial (...) os direitos sociais máximos devem ser obtidos na via do exercício da cidadania reivindicatória e da prática orçamentária” (TORRES, 2009, p. 80/81), ou seja, diante dos desvios políticos, cabe ao judiciário intervir ao menos para garantir o acesso ao mínimo existencial dos direitos fundamentais.

E assim tem procedido o Supremo Tribunal Federal com várias decisões que intervém na política pública penitenciária, como foi o caso do RE $n^{\circ} 580.252 / \mathrm{MS}$ em que se admitiu a possibilidade dos presos serem indenizados por danos morais, caso estejam cumprindo pena em condições humanas degradantes e do RE $n^{\circ}$ 592.581/RS em que se reconheceu a possibilidade do Judiciário condenar a União e os Estados a realizarem reformas ou construir novos presídios, independentemente da dotação orçamentária.

Percebe-se, portanto, que o Supremo tem seguido uma linha de intervenção na política pública penitenciária, relevando, inclusive, a reserva do possível e a existência de dotações orçamentárias específicas, na tentativa de garantir que ao menos o núcleo mínimo dos direitos fundamentais dos presidiários seja efetivado.

A máxima intervenção do judiciário na política pública analisada ocorreu por meio da declaração do Estado de Coisas Inconstitucionais na ADPF $n^{\circ}$ 347. A referida ADPF foi ajuizada pelo Partido Socialismo e Liberdade - PSOL, encontrando-se sob a relatoria do Ministro Marco Aurélio. Pleiteava-se que fosse reconhecido o Estado de Coisas Inconstitucional sobre o sistema penitenciário brasileiro, bem como fossem adotadas providências estruturais com o fito de debelar as sucessivas violações aos direitos fundamentais dos detentos (CAMPOS, 2016, p. 285).

Alejandro Diaz (2013) elucida que o “Estado de Coisas Inconstitucionais” é uma criação da Corte Constitucional Colombiana e não da Constituição política, surgindo da necessidade de superação do quadro de violação massiva, sistemática, coletiva e reiterada dos direitos fundamentais consagrados na Constituição e como consequência de sua declaração, exorta que as autoridades competentes, sejam estatais ou privadas, atuem em um prazo razoável e peremptório, adotando todas as medidas cabíveis para superar o estado em virtude da ausência ou má prestação de uma política pública.

O Estado de Coisas Inconstitucionais surge na tentativa de evidenciar as falhas da política econômica implementada pelos Governos, buscando torná-las menos rígidas e mais 
consentâneas com as necessidades sociais (GÓMEZ -PINTO, 2012, 12). Esse novo papel da Corte Constitucional permitirá que essa garanta uma aproximação da economia com a justiça constitucional.

Nesse sentido, o Estado de Coisas Inconstitucionais tem como principal catalizador a má utilização do gasto público, o que resulta na inefetividade de certa política pública, comprometendo o acesso da população aos direitos fundamentais constitucionalmente assegurados, ou seja, a raiz do problema de violações massivas e estruturais da dimensão objetiva dos direitos fundamentais está nos desvios do gasto público.

Essa afirmação fica claramente evidenciada se analisarmos como o Supremo se portou após o reconhecimento da existência de um Estado de Coisas Inconstitucionais sobre a política pública penitenciária. Em setembro de 2015, por ocasião da apreciação da medida cautelar da ADPF $n^{\circ} 347 / D F$, o STF determinou que os juízes e Tribunais observassem os artigos 9.3 do Pacto dos Direitos Civis e Políticos e 7.5 da Convenção Interamericana de Direitos Humanos; que as audiências de custódia fossem realizadas em até 90 (noventa) dias em todo o território nacional e que a União liberasse toda a verba contingenciada do Fundo Penitenciário Nacional (FUNPEN), abstendo-se de realizar novas contenções.

Observa-se, portanto, que logo após a declaração do ECI, a postura do Judiciário foi imediatamente intervir na utilização do princípio fundo de financiamento da política penitenciária, qual seja: o FUNPEN, o qual, conforme desenvolvido na seção anterior, tem passado por históricos períodos de contingenciamento. Conforme afirma Cass Sustein e Stephen Holmes (2000, p. 19): “Um direito legal existe, na realidade, apenas quando e se tiver custos orçamentários”, ou seja, a Constituição, com todos os direitos fundamentais que prescreve, é refém da Administração Pública, na medida em que só terá efetividade se existir dotação orçamentária voltada para a execução de tal direito (OTERO, 2009, p. 104/105).

O principal desafio está, portanto, em assegurar que a escolha política acerca do gasto público seja realizada de forma ética, atendendo na maior medida possível todas as necessidades sociais. Assim, ao intervir no orçamento, a atuação do Judiciário deve se pautar no combate ao fenômeno do rent-seeking, ou seja, deve-se impedir que as decisões políticas sejam tomadas apenas em benefício de certos grupos politica e economicamente organizados, visando reduzir o abismo existente entre tributação e gasto público e garantindo a observância ao interesse público.

Conclui-se, portanto, que a ineficiência na realização do gasto público gera inexoravelmente a inobservância aos direitos fundamentais e nessa medida a declaração de um 
Estado de Coisas Inconstitucionais poderá conferir maior transparência na realização do gasto, na medida que após a declaração desse instituto a Corte deve convocar os Poderes Executivos e Legislativo para que esses tracem planos de ação na tentativa de melhorar o serviço público judicializado, indicando quanto e como as receitas públicas serão dispendidas.

Defende-se, portanto, que a intervenção do judiciário sobre as escolhas políticas orçamentárias por meio do Estado de Coisas Inconstitucionais poderá ser um importante mecanismo de controle do gasto público na medida em que as distorções de investimento no serviço judicializado deverão ser corrigidas.

Acredita-se, também, que o ECI será mais eficiente no controle do gasto em se aproximando a estrutura do Compromisso Significativo, cabendo ao Judiciário apenas intermediar o dialogo entre a os poderes políticos (Executivo e Legislativo), para que esses estabeleçam um plano de ação, definindo como ocorrerão os investimentos no serviço deficitário e ao Judiciário cumpre o papel de fiscalizar a execução do compromisso assumido (CHENWI; TISSINGTON, 2010, p. 09).

\section{A INTERVENÇÃO DO JUDICIÁRIO NA EXECUÇÃO ORÇAMENTÁRIA DA POLÍTICA PÚBLICA PENITENCIÁRIA}

Pelo exposto, tem-se que uma má gestão das receitas e consequentemente do gasto público pelos gestores conduz a uma situação de inefetividade dos direitos fundamentais. Nesse sentido, o orçamento não pode mais ser encarado apenas como uma lei em sentido formal, mas deve ser enxergado como o principal instrumento de efetivação dos direitos.

Assim, no que concerne a política pública penitenciária percebe-se que um dos principais problemas de sua ineficiência perpasse a falta de interesse político em empregar as verbas do fundo especial FUNPEN para implementar os objetivos que embasaram a sua criação. Nesse caso, a intervenção do Judiciário recai sobre uma situação em que há programação de recursos e esses estão disponíveis. Ocorre que a Administração faz a opção política em contingenciar tais recursos ao invés de aplica-los.

É sabido que o contingenciamento das despesas é uma faculdade reservada ao Administrador, entretanto o referido contingenciamento deve ser feito de maneira justificada e razoável, sem comprometer a exequibilidade da política pública fixada no orçamento, uma vez que a lei orçamentária reflete o juízo de admissibilidade realizado pelo Legislativo (MAURÍCIO JUNIOR, 2009, p. 266) e desconsiderá-lo poderá acarretar severas crises institucionais. 
Ademais, os contingenciamentos não podem impedir a prestação de um direito fundamental pelo Estado. Assim, quando a reserva de contigência obsta a execução da política pública cabe ao judiciário intervir a fim de assegurar que a lei orçamentária, nos termos em que foi aprovada pelo Legislativo, seja efetivada.

Nesses termos, Eduardo Santos Carvalho (2004, p. 80) aduz que uma suposta autonomia do Executivo em decidir unilateralmente sobre a conveniência e oportunidade em implementar ou não certo direito social cessou em com o advento da Constituição de 1988, em que ficou instituída a obrigação do Estado em prestar direitos fundamentais, de modo que afirmar que apenas a Administração seria capaz de definir o conceito de interesse público, resulta na negação da vontade popular, execrando aqueles grupos com insignificante ou ausente participação política.

Nesses termos, a discricionariedade administrativa deve ser balizada pela Lei e não o contrário. Logo:

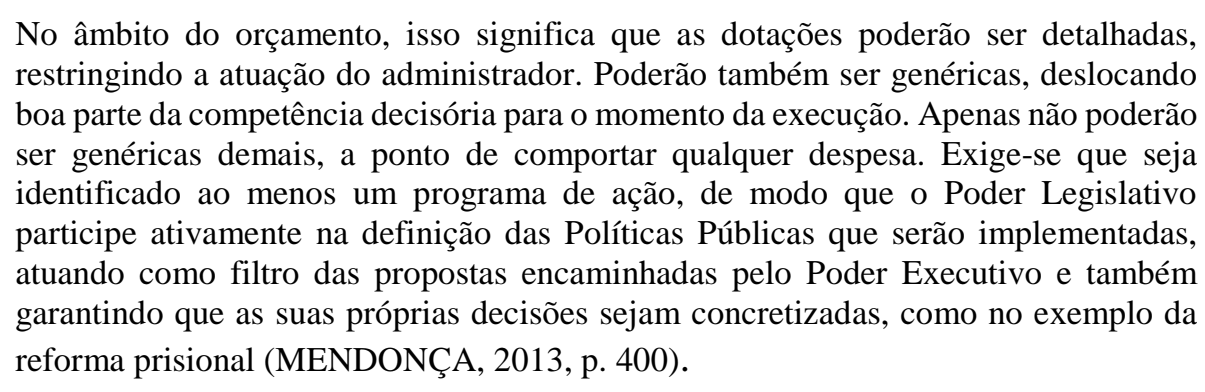

Pelo exposto, a decisão administrativa pela realização da reserva de contingência deve ser motivada, evidenciando que "sua conduta guarda relação com a realidade fática e está inserida no espaço de liberdade deixada pela ordem jurídica” (MENDONÇA, 2013, p. 404), guardando, portanto, congruência com a decisão legislativa pautada no orçamento.

Ademais, há de frisar-se que o papel dos direitos fundamentais está em garantir a limitação do Poder Estatal, bem como viabilizar a participação popular e democrática nas decisões estatais (ASÍS, 2000, p. 99). Assim, a não execução orçamental quando existem recursos disponíveis para tanto, em razão de decisão política imotivada, contribui para violação de direitos fundamentais mais básicos, na medida em que desconsidera os anseios e necessidades sociais, além de afastar o controle social sobre o crivo da discricionariedade autorizada, o que, em verdade, evidencia conduta ilícita que enseja a intervenção judicial para a correção das distorções.

Tal intervenção, entretanto, não deve se dar ditando como o gasto público ocorrerá, mas sim compelindo a Administração a executar o orçamento nos termos em que esse foi 
aprovado ou justificar a impossibilidade de fazê-lo, mediante a apresentação de dados concretos em que se evidencie que a receita prevista não foi auferida. Nesse sentido, defende-se que o controle judicial sobre a execução do orçamento deve ocorrer como meio de resistência às investidas dos Poderes Políticos que venham a representar qualquer ameaça à efetividade dos direitos individuais ou sociais e, assim, "os poderes estatais podem, tendo em vista a função pedagógica das decisões do Tribunal Constitucional, ser educados na lealdada à Constituição para, então, exercitá-la diariamente com uma atuação conforme a Constituição e aos Direitos Fundamentais” (BIAGI, 2005, p. 102).

Conclui-se que os recursos públicos devem ser investidos em políticas capazes de empreender a efetivação do texto constitucional, de forma que enquanto o conteúdo essencial dos direitos fundamentais não tiverem sido alcançados, outras políticas não prioritárias do ponto de vista constitucional terão de aguardar (BARCELLOS, 2006, p. 48).

Por todo o exposto, defende-se que a não execução da política pública penitenciária, em razão dos elevados níveis de contingenciamento nas receitas do FUNPEN, principal instrumento de financiamento dessa política, faz com que os presidiários enfrentam situações de violação massiva de seus direitos fundamentais, de forma que a intervenção judicial para corrigir tais distorções torna-se premente, uma vez que, conforme analisamos, há recursos suficientes ao financiamento de tal serviço público, faltando, em verdade, interesse político, sobretudo por parte do Executivo em implementar a política tal como essa fora prevista no orçamento. A intervenção judicial, por sua vez, não deve direcionar a forma pela qual o gasto deve ocorrer, mas sim garantir que a lei orçamentária seja cumprida e que as receitas auferidas sejam gastas com as finalidades que motivaram a sua arrecadação, enfatizando que a noção de orçamento autorizativo não dá direito a não execução orçamentária.

\section{CONCLUSÃO}

Conclui-se que a má prestação da política pública penitenciária perpassa, sobretudo, a questão orçamentária, uma vez que a principal verba destinada ao seu financiamento, o FUNPEN, é historicamente contingenciado, tendo sido aplicado sempre em patamares inferiores àqueles previstos nas Leis Orçamentárias.

Para além da questão do gasto, a inefetividade dessa política enfrenta outros problemas, tais como a cultura encarceradora que permeia a atuação judicial no Brasil, o que faz com que nossa população penitenciária tenha um crescimento superior ao crescimento demográfico do país. Além da falta de transparência dos dados oficiais acerca de investimento 
e programas voltados a concretização da política penitenciária, os quais se encontram defasados, de modo que as informações disponíveis não são oriundas do governo, mas fruto de estudos realizado pela iniciativa privada, sobretudo por Organizações Não Governamentais (ONGs), dificultando o controle social, afinal não se sabe com exatidão, como e em que as verbas do FUNPEN estão sendo efetivamente aplicadas.

O subfinanciamento gera, sem dúvidas, o não acesso aos direitos fundamentais mais básicos pelos presidiários, os quais enfrentam situações subumanas no interior dos presídios. Tem-se, assim, que a má gestão do gasto público, sobretudo quando esse se volta apenas para atender aos interesses os detentores de poder econômico e político, gera uma situação de desequilíbrio social e descrédito institucional, na medida em que o orçamento é encarado como uma peça de ficção em que o Executivo decide, sem qualquer motivação, em que vai ou não investir, criando a falsa noção de que há direito a não execução orçamental, afastando os setores mais humildes ou sem representação política do acesso aos direitos fundamentais mais básicos.

Esse subfinanciamento encontra embasamento, muitas vezes, na dimensão autorizativa do orçamento, a qual é equivocadamente compreendida como direito a não executar a lei orçamentária. Em verdade, essa característica do orçamento deve ser utilizada apenas para evitar engessamentos, permitindo ao gestor alterar os níveis de gasto somente quando as receitas previstas inicialmente não se concretizarem ou quando os gastos previsto mostrarem-se inadequados para o alcance das necessidades sociais, ou seja, não há direito a não executar o orçamento. No que concerne a discricionariedade que permeia as reservas de contingencia, tem-se que essas devem ser justificadas, elucidando em que medida o contingenciamento contribuirá mais para o alcance do interesse público que a execução da rubrica nos termos em que se encontra estabelecida no orçamento.

Assim, a falta de ética e o descompromisso na realização do gasto público ensejam o surgimento de situações de violação massiva e estrutural dos direito fundamentais, tornando-se possível a declaração de um Estado de Coisas Inconstitucionais, como foi feito pelo Supremo em setembro de 2015.

A intervenção judicial sobre a execução do orçamento por meio da declaração do Estado de Coisas Inconstitucional poderá ser um mecanismo útil para conferir maior transparência ao gasto público. Para tanto, o judiciário convocar aos poderes políticos para que tracem planos de ação, especificando como irão realizar o gasto, a fim de melhorar a prestação da política que se encontra deficitária. Defende-se, assim, que a intervenção do judiciário na execução do orçamento não pode ser no sentido de impor como o gasto público deve ser 
realizado, mas sim indicar que há problemas na gestão orçamentária e que essa deve ser revista, aplacando a discricionariedade contra legem do Executivo.

Nesses termos, acredita-se que a declaração do Estado de Coisas Inconstitucional nos termos em que foi adotado no Brasil não conseguirá empreender os resultados esperados, na medida em que nesse caso o Supremo interviu diretamente no orçamento, usurpando funções típicas dos poderes políticos, sem estabelecer, também, qualquer mecanismo de fiscalização acerca do cumprimento da decisão.

Por isso, conclui-se que a má gestão do gasto público pode, sem dúvida, ensejar a intervenção do judiciário na execução do orçamento, na medida em que a lei orçamentária não é apenas lei em sentido formal e a intervenção judicial é possível para garantir ao menos a prestação do núcleo mínimo dos direitos, como defende Ricardo Lobo Torres. Ocorre que essa intervenção não pode ocorrer de forma solipsista pelo Judiciário, o qual deve convocar os poderes políticos, para que esses sim indiquem em que e como a verba pública poderá ser empregada para garantir a concretização do texto constitucional.

Nossa proposta é que a intervenção do judicial na execução orçamentária apenas ocorra em situações extremas, em que a má gestão com o gasto público, aliada a discricionariedade antijurídica nas reservas de contingência, estão impedindo a concretização do mínimo existencial dos direitos. Assim, não é toda e qualquer restrição a direitos que poderá ensejar a intervenção judicial, afinal o orçamento é limitado e cabe ao gestor realizar as chamadas escolhas trágicas.

Havendo a intervenção, a qual, frisa-se, deve ocorrer apenas nessas situações extremadas, não cabe o judiciário direcionar onde a verba deve ser aplicada. Por isso, sugeriuse que nesses casos as decisões judiciais fossem embasadas em compromissos significativos, estabelecidos pelos poder políticos, cabendo ao judiciário apenas fiscalizar seu cumprimento e sancionar os gestores responsáveis quando o compromisso assumido não fosse observado.

Destaca-se que o presente trabalho apresenta algumas limitações, na medida em que não se discutiu quais meios de fiscalização e de sanção seriam cabíveis na investigação de cumprimento do compromisso significativo, o que será fruto de trabalhos posteriores, por não ser o escopo desse. 


\section{REFERÊNCIAS BIBLIOGRÁFICAS}

ASÍS, Rafael de. Las Paradojas de los derechos fundamentales como límites al poder. Madrid: Dykson, 2000.

BARCELLOS, Ana Paula de. Neoconstitucionalismo, Direitos Fundamentais e Controle das Políticas Públicas. In: SARMENTO, Daniel; GALDINO, Flávio. Direitos Fundamentais: Estudos em homenagem ao Professor Ricardo Lobo Torres. Rio de Janeiro: Renovar, 2006.

BIAGI, Claudia Perotto. A Garantia do Conteúdo Essencial dos Direitos Fundamentais na Jurisprudência Constitucional Brasileira. Porto Alegre: Sergio Antonio Fabris, 2005.

BRASIL. MINISTÉRIO DA JUSTIÇA. DEPEN - Departamento Penitenciário Nacional. Levantamento nacional de informações penitenciárias - INFOPEN. Brasília: Ministério da Justiça - DEPEN, junho de 2014.

. MINISTÉRIO DA JUSTIÇA. Fundo Penitenciário Nacional em Números.

Brasília: Ministério da Justiça, 2012.

BUCHANAN, James; MUSGRAVE, Richard A. Public finance and public choice: two contrasting visions of state. Cambridge/London: The MIT Press, 1999.

CAMPOS, Carlos Alexandre de Azevedo. Estado de Coisas Inconstitucional. Salvador: Juspodium, 2016.

CARVALHO, Eduardo Santos. Ação Civil Pública: Instrumento para implementação de prestações estatais positivas. Revista do Ministério Público. Rio de Janeiro, n 20, jul/dez. 2004.

CAVALCANTE, Denise Lucena; CABRAL, Denise Maciel de Albuquerque. Os custos das políticas públicas: Um olhar para o orçamento com foco no gasto. Revista de Direito Internacional, Econômico e Tributário, Brasília, v. 1, n. 9, p.1-18, jan. 2014. Semestral.

CHENWI, Lilian; TISSINGTON, Kate. Engagingmeaningfully with government on socioeconomic rights: A focus on the right to housing. Western Cape: Community Law Centre, 2010.

CONTAS ABERTAS. Descaso: governo tem R\$ 3,3 bi “parados" para reforma e ampliação de presídios. Contas Abertas, Goiânia, 28 out. 2016. Disponível em: $<$ http://www.contasabertas.com.br/site/noticias/descaso-governo-tem-r-33-bi-parados-parareforma-e-ampliacao-de-presidios>. Acesso em: 18 nov. 2017.

Superlotação: governo tem R\$ 2,5 bilhões parados para presídios. 2017.

Disponível em: <http://contasabertas.com.br/site/orcamento/superlotacao-governo-tem-r-25bilhoes-parados-para-presidios>. Acesso em: 18 nov. 2017.

CONTI, José Maurício. Levando o direito financeiro a sério. São Paulo: Blücher, 2016. 
COSTA, Pietro. Soberania, Representação, Democracia: ensaios de história do pensamento jurídico. Trad. Alexander R. de Castro et al. Curitiba: Juruá, 2010.

DIAZ, Alejandro Arango. Del estado de cosas inconstitucional. Artículos maestría en derecho Universidadad Sergio Arboleda - Santa Maria. 10 jun 2013. Disponível em $<$ http://derechojusticiaypaz.blogspot.com.br/>. Acesso em: 25 nov.2017.

GALDINO, Flávio. Introdução à Teoria dos Custos dos Direitos: Direitos não nascem em árvores. Rio de Janeiro: Lumen Juris, 2005.

GÓMEZ -PINTO, Luis Ricardo. El juez de las políticas públicas: Del estado de cosas inconstitucional en la política econômica. $1^{\text {a }}$ Edição. Bogotá: Pontificia Universidad Javeriana. Faculta de Ciencias jurídicas: Grupo Editorial Ibañez. 2012.

HOLMES, Stephen; SUNSTEIN, Cass R. The cost of rights: why liberty depends on taxes. New York: Norton, 2000.

LOCHAGIN, Gabriel Loretto. A flexibilidade da execução orçamentária. 2012. 225 f. Dissertação (Mestrado em Direito Econômico e Financeiro) - Universidade de São Paulo, São Paulo. 2012. Disponível em: < http://www.teses.usp.br/teses/disponiveis/2/2133/tde29082013-111525/pt-br.php>. Acesso em: 18 nov. 2017.

MARTINS, Guilherme Waldemar D’oliveira. Consolidação Orçamental e Política Financeira. Coimbra: Almedina, 2014.

MAURÍCIO JÚNIOR, Alceu. A revisão judicial das escolhas orçamentárias: a intervenção judicial em políticas públicas. Belo horizonte: Fórum, 2009.

MENDONÇA, Eduardo. Da faculdade de gastar ao dever de agir: O esvaziamento contramajoritário de políticas públicas. In: SARLET, Ingo Wolfgang; TIMM, Luciano Benetti. Direitos Fundamentais, orçamento e "reserva do possível". 2. ed. Porto Alegre: Livraria do Advogado, 2013.

MINISTÉRIO DA JUSTIÇA E SEGURANÇA PÚBLICA. Política Penal. 2017. Disponível em: <http://www.justica.gov.br/seus-direitos/politica-penal>. Acesso em: 18 nov. 2017.

NEVES, Marcelo. A Constitucionalização Simbólica. São Paulo: Wmf Martins Fontes, 2007.

OLIVEIRA, Cláudio Ladeira de; FERREIRA, Francisco Gilney Bezerra de Carvalho. O Orçamento Público no Estado Constitucional Democrático e a Deficiência Crônica na Gestão das Finanças Públicas no Brasil. Sequência, Florianópolis, v. 76, maio 2017. Quadrimestral.

OTERO, Paulo. Direito Constitucional Português, vol. I, Identidade Constitucional: Almedina. 2009.

PETTER, Lafayete Josué. Direito Financeiro. 5. ed. Porto Alegre: Verbo Jurídico, 2010.

TORRES, Ricardo Lobo. Direito ao mínimo existencial. Rio de Janeiro: Renovar, 2009. 
. Ricardo Lobo. Tratado de Direito Constitucional Financeiro e Tributário: orçamento na Constituição. 3. ed. Rio de Janeiro: Renovar, 2008. 